Contract No. and Disclaimer:

This manuscript has been authored by Savannah River Nuclear Solutions, LLC under Contract No. DE-AC09-08SR22470 with the U.S. Department of Energy. The United States Government retains and the publisher, by accepting this article for publication, acknowledges that the United States Government retains a non-exclusive, paid-up, irrevocable, worldwide license to publish or reproduce the published form of this work, or allow others to do so, for United States Government purposes. 


\title{
A Comparison of Two Thermal Insulation and Structural Materials for use in Type B Packagings
}

\author{
Paul S. Blanton \\ Savannah River National Laboratory \\ Aiken, South Carolina \\ paul.blanton@srnl.doe.gov
}

\author{
Kurt R. Eberl \\ Savannah River National Laboratory \\ Aiken, South Carolina \\ kurt.eberl@srnl.doe.gov
}

\author{
Paul T. Mann \\ National Nuclear Safety Administration \\ Albuquerque, NM \\ pmann@doeal.gov
}

\begin{abstract}
This paper presents the summary of design features and test results of two Type B Shipping Package prototype configurations comprising different insulating materials developed by the Savannah River National Laboratory (SRNL) for the Department of Energy. The materials evaluated, a closed-cell polyurethane foam and a vacuformed ceramic fiber material, were selected to provide adequate structural protection to the package containment vessel during Normal Conditions of Transport (NCT) and Hypothetical Accident Condition (HAC) events and to provide thermal protection during the HAC fire. Polyurethane foam has been used in shipping package designs for many years because of the stiffness it provides to the structure and because of the thermal protection it provides during fire scenarios. This comparison describes how ceramic fiber material offers an alternative to the polyurethane foam in a specific overpack design. Because of the high operating temperature $\left(\sim 2,300^{\circ} \mathrm{F}\right)$ of the ceramic material, it allows for contents with higher heat loads to be shipped than is possible with polyurethane foam. Methods of manufacturing and design considerations using the two materials will be addressed.
\end{abstract}

\section{PROTOTYPE DESIGN OVERVIEW}

The prototypes developed and tested were part of SRNL's evaluation for the certification documentation of the Bulk Tritium Shipping Package (BTSP), a new Type B packaging developed for the DOE to replace an expiring tritium packaging. The BTSP package weighs approximately $650 \mathrm{lbs}$, with contents, and is $50-1 / 2$ inches high by $24-1 / 2$ inches in outside diameter. The maximum content heat load for the BTSP is 50 -watts from tritium decay. The BTSP design consists of two primary assemblies, an outer Drum (overpack) Assembly and an inner Containment Vessel (CV) Assembly.

The Drum Assembly, including an integrally welded liner and bolted lid, protects the CV from damage during NCT and HAC events. The baseline design of the BTSP drum body incorporates polyurethane foam between the drum liner and the drum outer shell. An alternate prototype design configuration replaces the polyurethane foam with a vacuum-formed ceramic fiber cylinder. The Drum lid weldment is attached to the Drum Body with twelve 5/8-inch heavy hex bolts. The Lid includes a vermiculite block for thermal insulation.

The CV is designed to hold tritium (process) containers and to prevent leakage of tritium from the CV under NCT and HAC. During transport, the CV rests on a silicone pad within the Drum Liner and is covered with a thermal insulating disk within the Drum Assembly. Figure 1 shows the major components of the BTSP Package.

The CV Assembly is fabricated from 304L stainless steel and weighs approximately 150 pounds and is $37-1 / 2$ inches high by 14 inches in outside diameter. The assembly has

This paper has been authored by Savannah River Nuclear Solutions, LLC under Contract No. DE-AC09-08SR22470 with the U. S. Department of Energy. The United States Government retains, and by accepting the article for publication, the publisher acknowledges that the United States Government retains, a non-exclusive, paid-up, irrevocable, worldwide license to publish or reproduce the published form of this work, or allow others to do so, for United States Government purposes. 
three primary components, the CV Body, the CV Lid and the CV Protective Cap. The CV components are fabricated to ASME B\&PVC, Division 1, Subsection NB requirements with a design pressure of 500 psig at $400^{\circ} \mathrm{F}$.

The primary closure of the CV Lid to the CV Body is achieved with sixteen high strength $1 / 2$-inch bolts compressing a metallic C-ring in a gland machined into the top of the CV Body; this closure along with the Stellite ${ }^{\circledR}$ metal tip of the bellows valve, provide the primary containment boundary for the contents.

A separate enclosure is formed on top of the CV Lid over the metal bellows valve and the quick-connect leak-test fitting by the CV Protective Cap secured with ten 5/16-inch socket head bolts. It also incorporates a metallic C-ring similar to, but smaller than, the seal in the primary CV Flange closure.

With the exception of the different Drum Body insulation materials, polyurethane foam and ceramic fiber, the two prototypes configurations compared in this paper are identical.

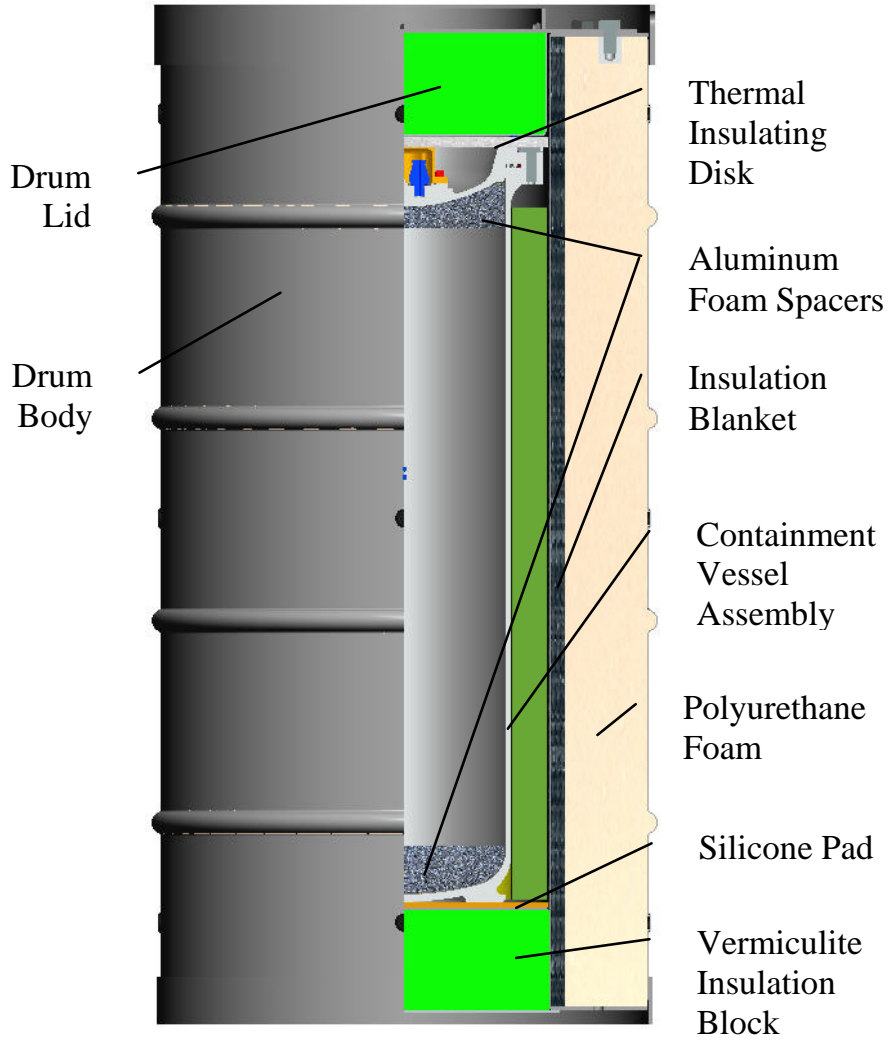

\section{TEST PROGRAM OVERVIEW}

The NCT and HAC Regulatory performance tests performed on the BTSP prototype packages were in accordance with the U.S. Nuclear Regulatory Commission (NRC) Regulation 10CFR71 and the National Nuclear Security Administration (NNSA) Safety Guide SG-600. All tests were performed according to SRNL-approved test procedures and a Test Plan which describe the scope of the tests to be performed, the task requirements, a list of required materials, equipment and services, quality requirements, test-site requirements, test personnel requirements and a test matrix to list the sequence of the tests performed. All tests, except the vibration tests, were conducted at the NovaTech facility in Lynchburg, VA. At the conclusion of each test, the prototype package was evaluated by NovaTech personnel to determine the extent of the damage incurred by the tests. Results are summarized in a Test Report.

Tests were performed on eight BTSP prototype packages labeled PSN-2 and PSN4 thru PSN-10. All prototypes were fabricated with the polyurethane insulation configuration with the exception of PSN-10 which had the vacuum-formed ceramic fiber insulation. The required tests and specific requirements and orientations were defined by SRNL in the testing contract with NovaTech [1].

The NCT tests performed include water-spray, 4-ft free-drop, penetration, compression tests, and vibration. The NCT vibration tests were performed on the polyurethane foam-filled prototype PSN-4 only. The HAC tests performed include the $30-\mathrm{ft}$ free-drop, crush, puncture and thermal (pool fire) tests.

In preparation for subsequent thermal (pool fire) performance tests temperature labels were applied at designated locations so that temperature excursions could be documented. Prior to conducting the regulatory performance tests, simulated contents were assembled into the prototype packages and the packages were closed in accordance with approved procedures.

Test orientations of the packages were chosen to maximize the damage to the packages and thereby maximize the potential for loss of containment of the BTSP CV. This paper summarizes the test results and performance of the two BTSP prototypes that provide the best comparison of the polyurethane foam and ceramic fiber configurations.

Figure 1 BTSP Package Overview 


\section{MANUFACTURING AND INSTALLATION OF THE POLYURTHANE AND CERAMIC FIBER MATERIALS}

\section{Polyurethane Foam}

The polyurethane foam insulation (Last-A-Foam ${ }^{\circledR}$ FR-3710) is produced and installed by General Plastics Manufacturing Co (Tacoma, WA) using proprietary processes and procedures. The two constituents of the liquid foam are combined prior to being injected through a 1-inch fill hole located in the bottom of an inverted drum.

When first mixed, the viscosity of the polyurethane liquid is roughly that of SAE 30 motor oil, and within minutes, begins reacting exothermically and sets to form a rigid, closed-cell, polyurethane foam. This reaction increases the surface temperature of the drum to about $150^{\circ} \mathrm{F}$, which then drops below $120^{\circ} \mathrm{F}$ in about an hour. As the reaction progresses, foam rises and solidifies at a rate of approximately 6 inches per minute. For the BTSP, foam installation can be performed using a single pour or in a two-step operation. If two steps are used, the first pour is adjusted to fill approximately $90 \%$ of the drum volume and the second pour completes the fill. Fill is confirmed by observation of foam extruding from the fill port and the three bottom vent holes. There are vent holes also in the drum outer wall to allow gasses to escape in the event of a fire; they are closed with Caplugs ${ }^{\circledR}$ prior to foaming.

\section{Vacuum-formed Ceramic Fiber Insulation}

The vacuum-formed ceramic fiber insulation (I-2300M) is produced by Thermal Ceramics, Inc., Burlington, Ontario. It is a fibrous bulk material, off-white in color, inorganic, and can be vacuum formed into various shapes. Fiber chemical composition and shape (length, diameter) are engineered depending on product use. It has a low thermal conductivity ( $\left.1 \mathrm{BTU}-\mathrm{in} . / \mathrm{hrft} 2^{\circ} \mathrm{F}\right)$ with a maximum temperature use range of 2300 to $3200^{\circ} \mathrm{F}$. The ceramic fiber is primarily alumina and silica, $32 \%$ and $68 \%$ by weight, respectively. [2]

In the vacuum forming process, ceramic fiber is mixed in a slurry bath in which the required shape is formed. Figure 2 illustrates a vacuum-form cylinder immediately after being lifted from the slurry bath. The vacuum fixture pictured comprises a top and bottom plate with a wire screen mesh inner cylinder. A vacuum draws the slurry through screened mesh pulling the liquid through and leaving the fibers to form the ceramic cylinder. The outside diameter and density of the vacuum-formed cylinder are controlled by process parameters (slurry viscosity, vacuum pressure and time). The pictured cylinder was formed in a few minutes.

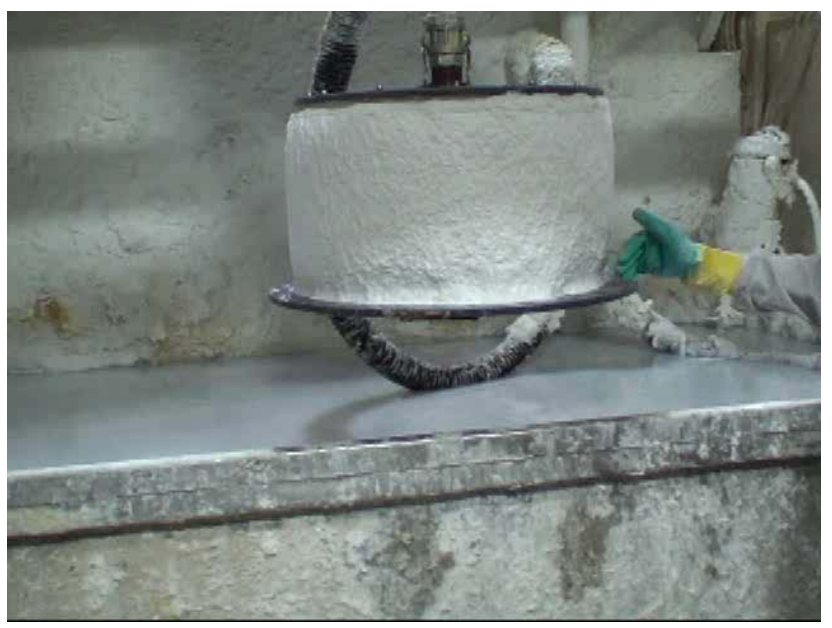

Figure 2

The three I-2300M cylinders where subsequently machined with interlocking shiplap joints to the final dimensions specified by SRNL. Figure 3 illustrates three final-machined cylinders that fit closely within the BTSP welded drum body.

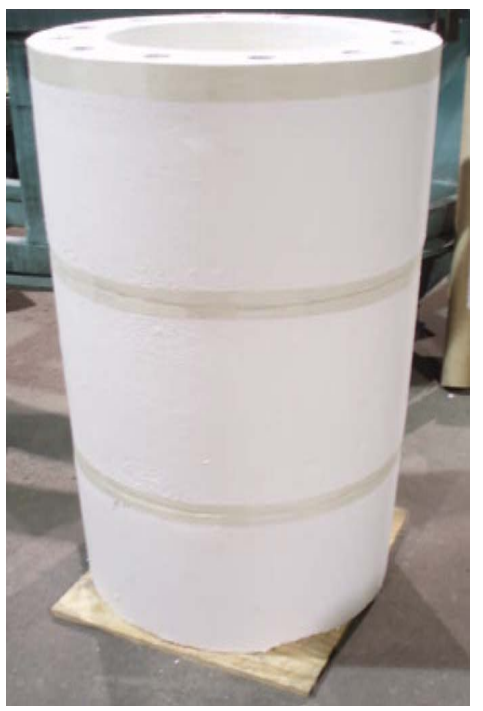

Figure 3

Prior to the assembly of the I-2300-M cylinder into the drum, the outside of the drum liner is wrapped with a thermal blanket (see Figure 4). The core material of the thermal blanket has similar thermal properties to that of the I-2300M. The blanket cover is a nylon cloth that provides a slick surface for insertion into stacked I-2300M cylinder assembly. 


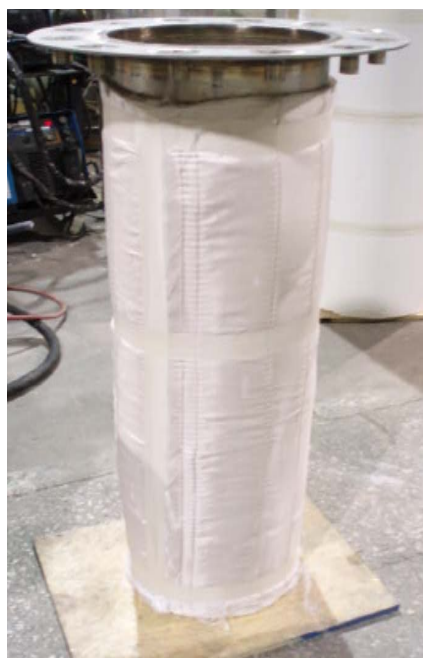

Figure 4

Following the drum liner installation, the I-2300M/liner subassembly is lowered into the BTSP drum as pictured in Figure 5. The outer diameter of the I-2300M is closely machined to maintain a tight fit with drum shell. This is evidenced by a portion of the I-2300M being scrapped off during assembly. The cylinder is pressed into the drum shell for a tight fit. After the I-2300M/liner is assembled into the drum, the final welds are made to complete the Drum Assembly.

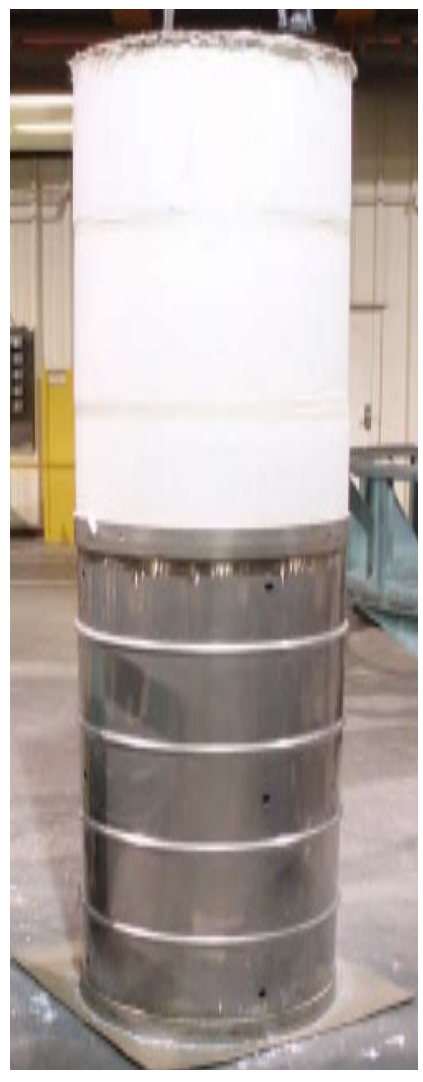

Figure 5

\section{PACKAGING TESTING PREPARATION}

For the purpose of comparing the thermal and structural performance of the two materials, General Plastics FR-3710 polyurethane foam and Thermal Ceramics I-2300M vacuum-formed ceramic fiber, this paper considers the three BTSP prototype packages labeled PSN-2, PSN-5 and PSN-10; PSN-2 and PSN-5 contained the foam and PSN-10 contained the I-2300M. PSN-5 was pre-heated prior to testing to evaluate the temperature effect on package performance. Although all three packages were subjected to NCT and HAC NRC Regulatory Tests, only the HAC testing and results will be presented: the $30-\mathrm{ft}$ free-drop, crush, puncture and thermal (pool fire) tests. These prototype packages were chosen for comparison since these three packages were tested under the same HAC crush, puncture and fire test orientations (see Table 1).

Prior to HAC testing, each BTSP prototype CV was assembled and confirmed to be leak-tight to less than or equal to 2 x 10-7 atm He cc/sec. Each package included temperature indicating labels strategically located on the CV and Drum Assembly to record the maximum attained temperatures that were recorded during the HAC testing.

\section{STRUCTURAL PACKAGING TESTING}

For the structural HAC tests, PSN-2 and PSN-10 were tested with the same initial temperatures $\left(77^{\circ} \mathrm{F}\right)$ and orientations which allows the test results to be compared directly. For the 30-ft drop of PSN-2 and PSN-10, each package was aligned with its center-of-gravity oriented over its top edge (CGT). Figure 6 shows PSN-2 with top edge oriented over its CG prior to being hoisted to $30-\mathrm{ft}$ and dropped.

\section{Table 1 Test Matrix}

\begin{tabular}{|l|l|l|l|c|}
\hline Pkg. ID & $\begin{array}{l}\text { Pkg } \\
\text { Temp. } \\
\left({ }^{\circ} \text { F }\right)\end{array}$ & $\begin{array}{l}\text { 30-ft } \\
\text { Drop }\end{array}$ & Crush & Puncture \\
\hline PSN-5 & 150 & Horiz & Horiz & Horiz \\
\hline PSN-2 & 77 & CGT & Horiz & Horiz \\
\hline PSN-10 & 77 & CGT & Horiz & Horiz \\
\hline
\end{tabular}

Note: PSN-2 and PSN-5 were filled with polyurethane foam and PSN-10 was filled with vacuum-formed ceramic fiber insulation. 


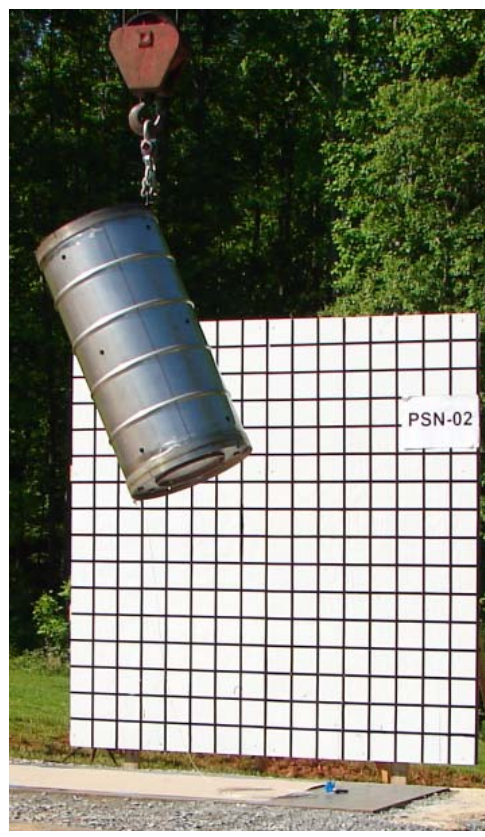

Figure 6 PSN-02 Prior to 30-Ft CGT Drop Test

Each of the three packages were oriented horizontally for the subsequent crush and puncture tests. Since the polyurethane foam softens with increasing temperature, PSN-5 was heated to $150^{\circ} \mathrm{F}$ prior to testing in order to observe the effects of the maximum (50-watt) payload. Since PSN-10 is filled with I-2300M, which is stable to $2300^{\circ} \mathrm{F}$, preheating prior to testing would have negligible effects.

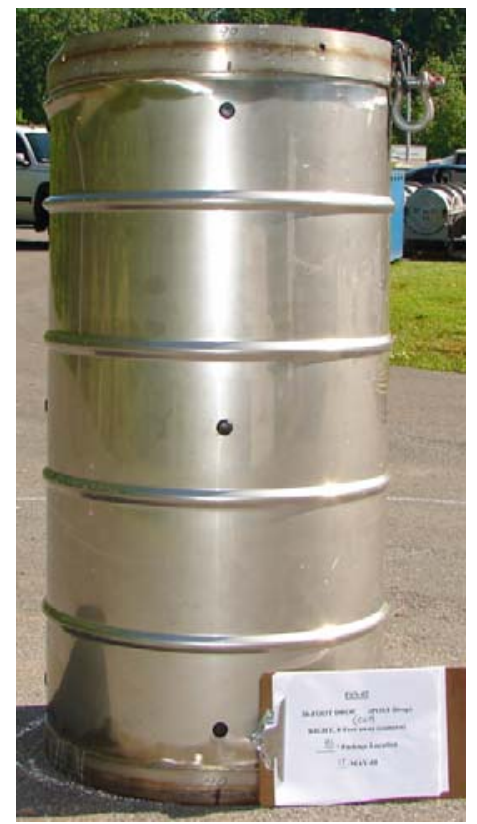

Figure 7 PSN-02 after the CGT 30-ft Drop Test
Figure 7 shows the damage observed on PSN-02 after the 30 -ft drop; the damage to PSN-10 was similar. PSN-02 is only slightly dented at the point of impact on its top rim. The drum shell is slightly buckled below the top rim. Overall the damage is superficial. The polyurethane foam is a relatively rigid material (modulus: $\sim 3.3 \mathrm{ksi}$ ) and little damage is typically observed from the $30-\mathrm{ft}$ drop on packages filled with polyurethane foam.

As expected, the prototype package with I-2300M (PSN-10) exhibited more damage from the 30-foot drop than the foam-filled packages (see Figure 8). The I2300M used in PSN-10 is significantly less stiff than polyurethane foam. At the point of impact, the top rim of the drum buckled into the side of the drum. Although the external damage for PSN-10 is greater, since more energy is absorbed by the overpack, less g-loading is imparted to the CV. Less g-loading to the CV (and contents) is a desirable package performance attribute.

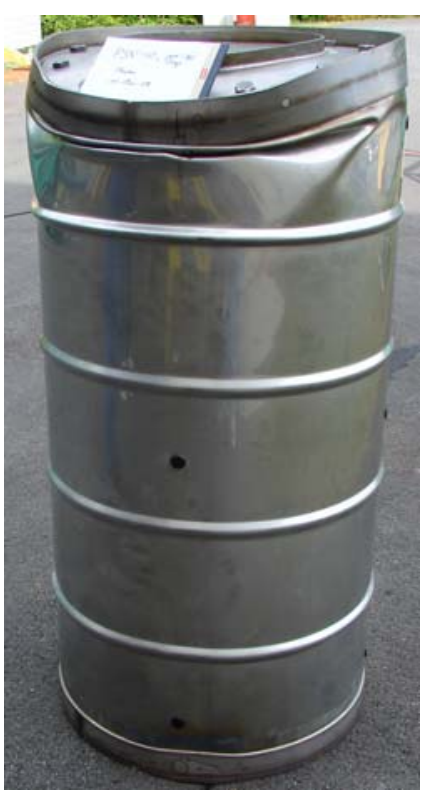

Figure 8 PSN-10 Post CGT 30-ft Drop

Prototype package PSN-5 was dropped horizontally and observed damage was minimal; there were surface scratches and slight denting of the rolling hoops.

The crush tests were performed on the three prototype packages subsequent to the 30 -foot drop tests. The crush test involved dropping a 40-in square, 2.4-inch thick, 1100 -lb. rigid plate from thirty feet onto the test packages. Each package were oriented horizontally with the damage from the 30-ft drop facing up towards the crush plate. The plate struck squarely in the middle of the package between the top and bottom reinforcing rings. Figure 9 shows PSN-10 positioned for the crush test. 


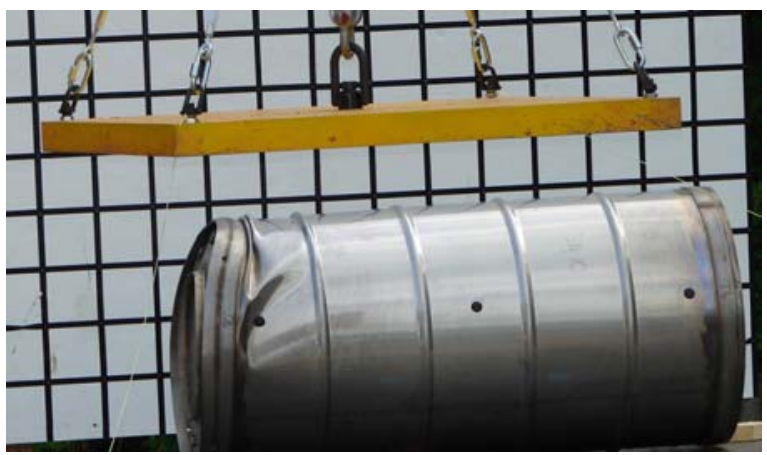

Figure 9 PSN-10 Prior to Crush Test

Damage to the polyurethane filled prototypes, PSN-2 and PSN-5, was minor. The drum wall in these two packages was flattened radially approximately 1 -inch on the impacted side. The flattened region was about 11-inches wided by 48-inches (approximately the width of the crush plate) as is captured in Figure 10. The side of the drum resting on the drop pad had little damage; the drum rolling hoops were not flattened.
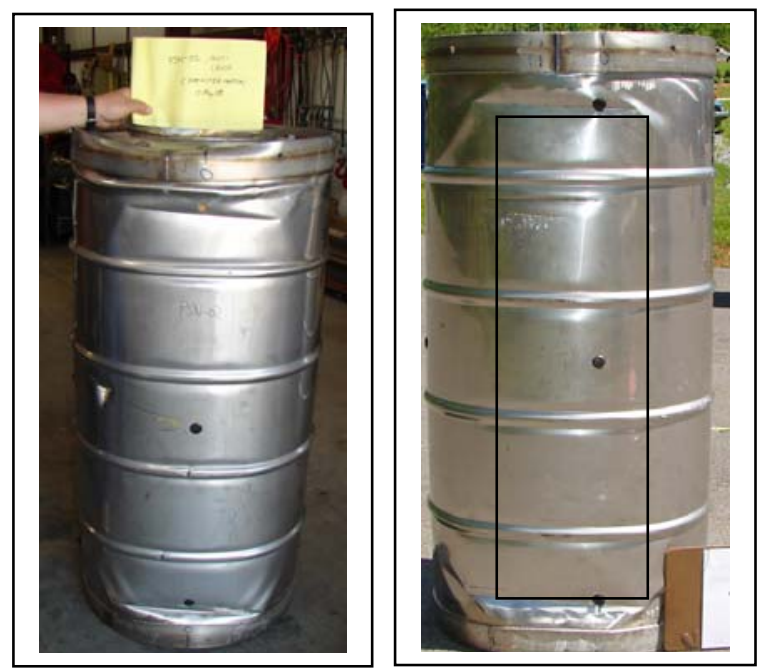

Figure 10 PSN-2 and PSN-5 after Crush Test

Damage to the I-2300M filled drum prototype, PSN-10, was greater than the damage to the foam-filled packages. The drum wall of PSN-10 was flattened radially approximately three inches. The flattened region was about 20 -inches wide by 48 -inches as depicted in Figure 11. The portion of the drum resting on the plate received little damage as evidenced by the drum rolling hoops not being flattened. Minimal damage to the bottom side of drum indicates that much of the impact energy was absorbed on the side of the package on which the drop plate impacted.
After the crush tests, the three prototype packages were subjected to puncture tests where the package was dropped forty inches onto a 6-inch diameter steel pin. Each package was oriented horizontally for the puncture tests. The depth of damage resulting from the puncture tests was similar for PSN-2 and PSN-10. Figure 12 illustrates the damage resulting from the puncture test for these two packages.

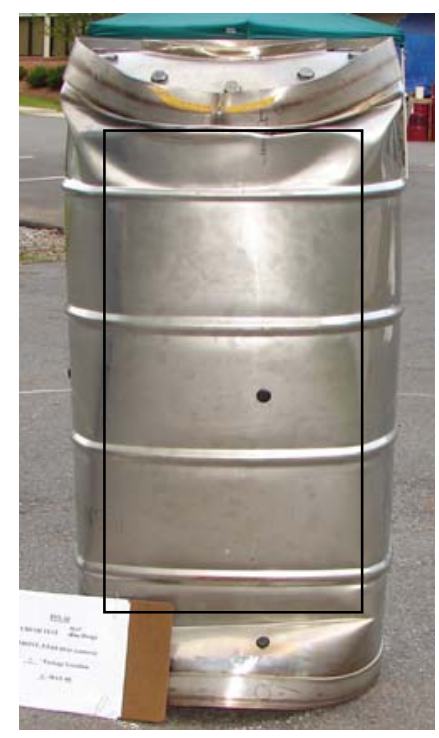

Figure 11 PSN-10 after the Horizontal Crush Test

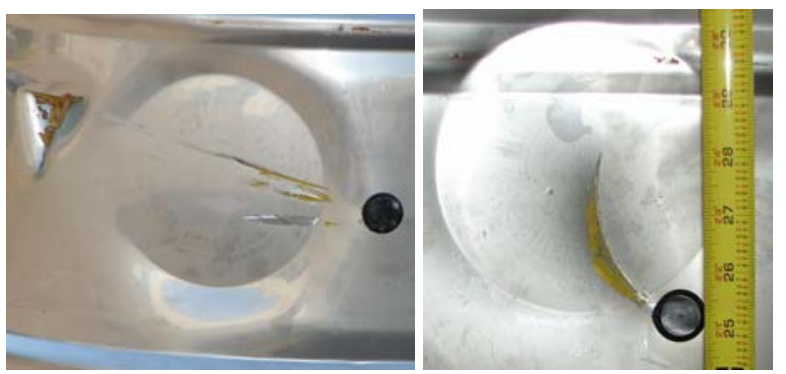

Figure 12 Observed damage from Puncture Tests for PSN-2 (left) and PSN-10 (right)

\section{THERMAL PACKAGING TESTING}

Following the HAC structural testing, each package was subjected to pool fire in accordance with 10 CFR71.73 which specifies a minimum $1,475^{\circ} \mathrm{F}$ for at least 30 minutes. The actual burns were at approximately $2,000^{\circ} \mathrm{F}$ for about 35 minutes. Thermocouples were attached to each of the prototype packages to monitor temperatures during the fire. The fire testing was performed at the South Carolina Fire Academy located in Columbia, SC under the direction of academy personnel. Figure 13 shows PSN-10 during the fire test. 


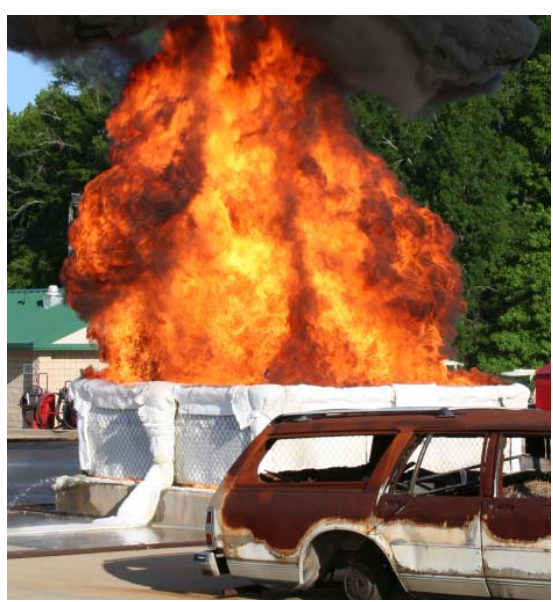

Figure 13 PSN-10 Fully Engulfed in Fuel Pool Fire

On completion of each burn the packages were allowed to cool within the fire pit before being handled. Figure 14 and Figure 15 show PSN-2 and PSN-10, respectively, staged in the pool fire pit after the fire. Both pictures were taken about five minutes after the fuel supply was stopped. Flames can be seen jetting from the vent holes in the drum shell of PSN-2. It is typical for the polyurethane foam to continue to burn and release gases after the pool fire has stopped. Flames are typically gone after about 10 minutes.

The white material seen in the vent holes of PSN-10 (Figure 15) is unburned, pristine I-2300M insulation. The insulation with a continuous operating temperature of $2300^{\circ} \mathrm{F}$ was unaffected by the fuel fire. After the fire tests, the packages were transported back to Savannah River Site (SRS) in Aiken, SC for destructive examination and evaluation.

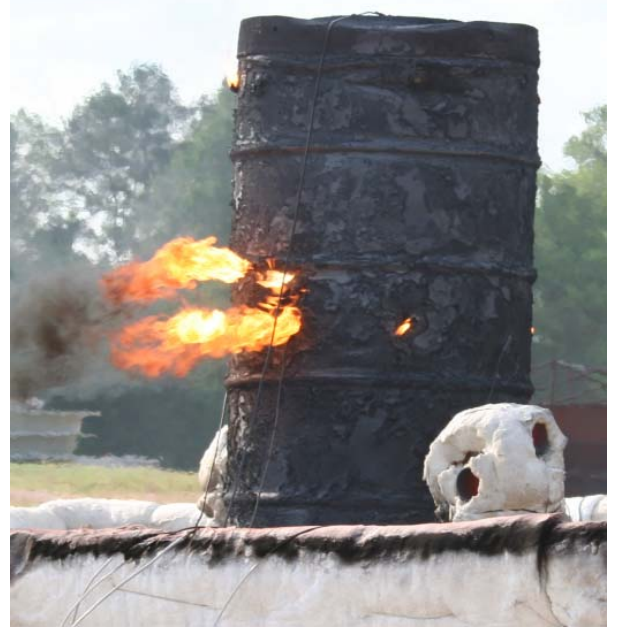

Figure 14 PSN-02 after Pool Fire Test

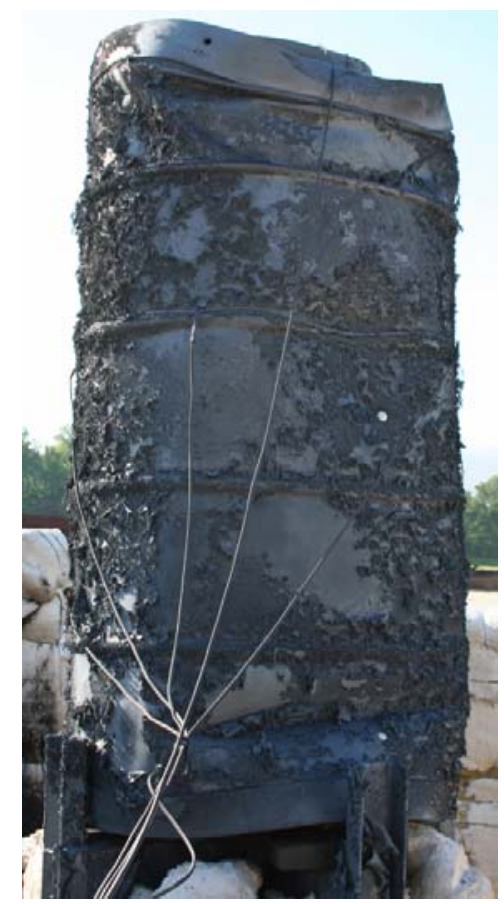

Figure 15 PSN-10 after Pool Fire Test

\section{PACKAGE EVALUATION}

The tested prototype packages were dismantled at SRS and their respective containment vessels were removed for examination and subsequent leakage testing (see Figure 16 and Figure 17). The temperature indicating labels on the CVs were recorded. The maximum recorded temperature on the outside of the CVs for the foam-filled and the I-2300M packages was about $250^{\circ} \mathrm{F}$ on the surface of the CV lid. This indicates that I-2300M provides the same level of thermal protection as does the polyurethane foam-filled package.

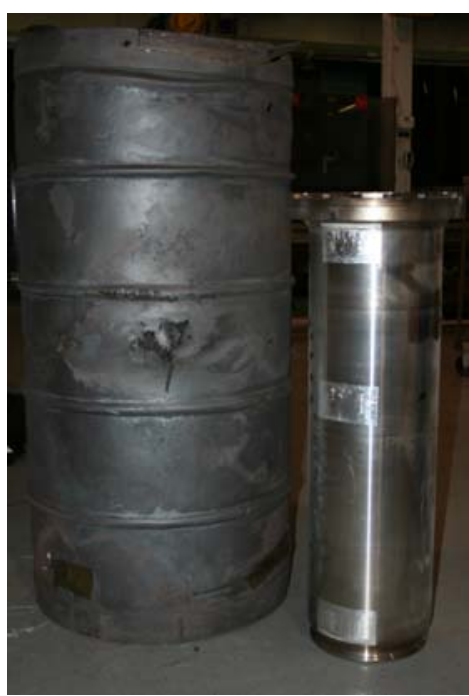

Figure 16 PSN-02 Post Burn CV Extracted 
As a confirmation that the $\mathrm{CV}$ did not lose containment as a result of the NCT and HAC testing, the extracted CVs were subjected to leakage-rate tests. Both the foam-filled and I-2300M filled packages passed the leakage-rate tests showing they remained leak-tight. Leak-tightness is the final confirmation that the performance of the package prototypes meets the test criteria.

In addition to the evaluation and leakage testing of the CVs, the foam filled package overpacks were destructively examined. Figure 17 depicts the foam filled region of a drum following the burn test. It is observed that the majority of the polyurethane foam is decomposed leaving only the black char. The degraded foam turns into irregular shaped char nodules with similar thermal conductivity characteristics of air. The char completely fills the void previously occupied by the polyurethane foam. Figure 17 shows the drum cut in half and the degraded foam excavated to reveal the inner liner of the drum. The three layers of the insulation blanket material were cut and pealed away to observe any structural damage to the overpack liner.

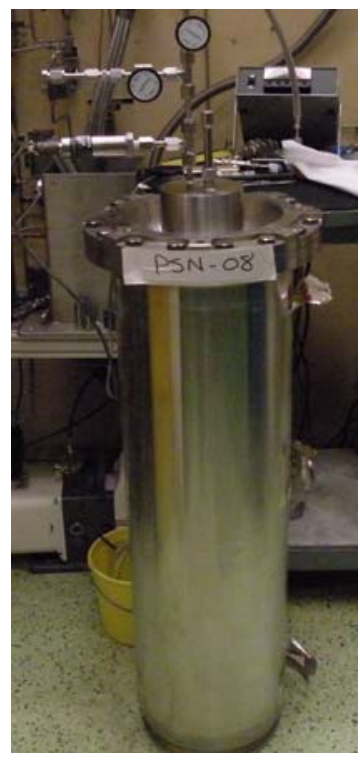

Figure 17 PSN-08 Post HAC Leak Testing

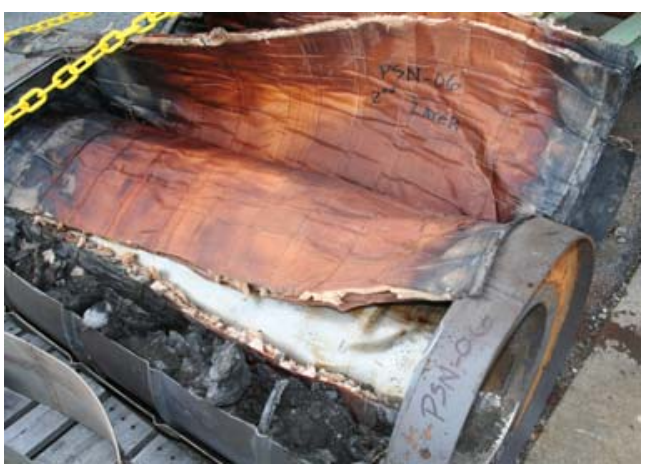

Figure 18 Post Burn Destructive Examination

\section{CONCLUSIONS}

NRC Regulatory tests were performed on BTSP prototype packages incorporating two different types of thermal and structural materials. Based on the post-test examination and testing, it is concluded that I-2300M insulation can be substituted for polyurethane foam and provide adequate structural and thermal protection to the CV. The I-2300M has the advantage that it can withstand temperatures significantly greater than polyurethane foam permitting higher heat load contents. Furthermore, the I-2300M material reduces the g-loading transferred to the $\mathrm{CV}$ because it allows more energy to be absorbed in the overpack during HAC structural tests.

\section{REFERENCES}

1. Structural Testing of the Bulk Tritium Shipping Package (BTSP) Prototypes, S-SOW-G-00003, Revision 6, May 30, 2008.

2. Thermal Ceramics, Product Data Brochure Canada and United States, 2009 Edition.

\section{DISCLAIMER}

This document was prepared in conjunction with work accomplished under Contract No. DE-AC09-08SR22470 with the U.S. Department of Energy.

This work was prepared under an agreement with and funded by the U.S. Government. Neither the U. S. Government or its employees, nor any of its contractors, subcontractors or their employees, makes any express or implied: 1 . warranty or assumes any legal liability for the accuracy, completeness, or for the use or results of such use of any information, product, or process disclosed; or 2. representation that such use or results of such use would not infringe privately owned rights; or 3. endorsement or recommendation of any specifically identified commercial product, process, or service. Any views and opinions of authors expressed in this work do not necessarily state or reflect those of the United States Government, or its contractors, or subcontractors. 